\title{
INSATISFAÇÕES PROJETADAS DE CONSUMIDORES DE BAIXA RENDA
}

\author{
DISSATISFACTION PROJECTED OF LOW INCOME CONSUMER
}

Recebido em 25.05.2014. Aprovado em 01.12.2014 Avaliado pelo sistema double blind review

DOI: http://dx.doi.org/10.12712/rpca.v8i4.456

\author{
Marcus Wilcox Hemais \\ marcus.hemais@iag.puc-rio.br \\ Pontifícia Universidade Católica do Rio de Janeiro - Rio de Janeiro- RJ - Brasil
}

\section{Leticia Moreira Casotti}

leticia@coppead.ufrj.br

Universidade Federal do Rio de Janeiro - Rio de Janeiro- RJ - Brasil

\begin{abstract}
Resumo
0 presente estudo tem como objetivo estudar como consumidores de baixa renda reagem quando em situações de insatisfação de consumo. Utilizou-se, para isso, a técnica projetiva de histórias temáticas para a coleta de dados. Foram identificadas duas perspectivas sobre como o consumidor reage quando insatisfeito. A primeira, ilustra um comportamento passivo sobre como resolver problemas de consumo, que, em geral, significa não reclamar e se conformar com o prejuízo. A segunda, diferentemente, ilustra uma reação contra a insatisfação, expressa por reclamações ou, até, adoção de medidas legais. Diferentemente do que a literatura aponta, o presente trabalho mostra que há consumidores de baixa renda que reclamam quando insatisfeitos, pois conhecem, pelos menos em discurso, seus direitos de consumo. Empresas devem atentar para tais reações desses consumidores, fugindo da racionalidade de que eles abrem mão de atendimento de qualidade, por valorizarem mais preços baixos.
\end{abstract}

\section{Palavras Chave:}

Insatisfação. Reclamação. Consumidor de baixa renda. Passivo. Reativo.

\begin{abstract}
:
The present study has the objective of researching how consumers in this segment react when dissatisfied. For this, the projective technique of thematic stories was used to collect the data. Two perspectives on how these consumers react when dissatisfied where perceived. The first, illustrates a passive behavior of how to resolve consumption problems, which, in general, means not complaining and conforming to the loss. The second, differently, illustrates a reaction against the dissatisfaction, expressed by complaining or, even, adopting legal action. Differently from what the literature points to, the present study shows that low income consumers do complain when dissatisfied, since they know, at least in discourse, their consumer rights. Companies should recognize the distinct reactions of low income consumers when dissatisfied. The rationality that these consumers prefer lower prices instead of better services seems to not be a reality.
\end{abstract}




\section{Key words:}

Dissatisfaction. Complaint. Low income. Consumer. Passive. Reactive.

\section{Introdução}

A preocupação em entender a insatisfação de consumidores tem gerado um número cada vez maior de estudos sobre o tema (ANDRADE; BALASSIANO; BRANDÃO, 2013; BEBER; ROSSI, 2006; ONYEASO, 2007;). Esses estudos concordam, com base no modelo de desconfirmação de expectativas de Oliver (2010), que a insatisfação ocorre quando o desempenho de um produto ou serviço não atende às expectativas do consumidor (FORBES, 2008; HALSTEAD; DRÖGE; COOPER, 1993; LAPRÉ; TSIKRIKTSIS, 2006).

No Brasil, a preocupação em entender esse comportamento pode ser explicada pelo fato de que aumenta o número de reclamantes em órgãos de defesa do consumidor. Dados do Sistema Nacional de Informações de Defesa do Consumidor (Sindec) mostram que, somente em 2012, foram cerca de dois milhões de atendimento nos Procons do país, um aumento de 19,7\% em relação ao ano anterior. Entre os setores mais reclamados estão os de telecomunicações, planos de saúde e financeiros (SISTEMA NACIONAL DO CONSUMIDOR, 2012).

Embora a reclamação seja uma forma de reagir a uma experiência de insatisfação, há diversas outras ações que o consumidor pode adotar (SANTOS; FERNANDES, 2010), tais como: retornar o produto à empresa, exigir o reparo do produto, tomar medidas legais, fazer boca-a-boca negativo, ou, até mesmo, fazer nada (CRIÉ, 2003; SINGH, 1990). Embora sempre exista algum tipo de reação, mesmo que essa seja passiva, nem sempre há a reclamação sobre a insatisfação (RICHINS, 1983).

Alguns estudos buscaram entender o perfil de consumidores insatisfeitos que não reclamam e o motivo de não o fazerem. Chebat, Davidow e Codjovi (2005) explicam que um motivo para esses indivíduos não reclamarem é a sensação de resignação; uma propensão natural a silenciar-se por achar que "a luta já está perdida" (p.330). Phau e Baird (2008) corroboram essa afirmação quando alegam que consumidores que não reclamam têm uma atitude mais pessimista em relação aos resultados da reclamação do que aqueles que expressam sua insatisfação. Heung e Lam (2003), por sua vez, defendem que o comportamento de reclamar está inversamente relacionado à idade, e positivamente a renda e educação. Ou seja, o quanto menor a renda e o grau de educação, menor a propensão a reclamar, o que sugere que consumidores pertencentes às camadas mais populares reclamam menos do que aqueles no topo da pirâmide.

A literatura recente sobre consumidores de baixa renda mostra esse mercado como uma grande oportunidade a ser explorada. O principal autor que vem defendendo essa tese é Prahalad (2006), que fala do potencial de quatro bilhões de indivíduos na base da pirâmide, com possibilidades, ainda que restritas, de consumir bens e serviços oferecidos por grandes empresas (PRAHALAD; HAMMOND, 2002; PRAHALAD; HART, 2002).

Diversos exemplos na literatura sobre consumo na base da pirâmide mostram como empresas adaptam seus produtos para mais bem atender esse mercado, obtendo lucros e, ao mesmo tempo, gerando consumidores satisfeitos, com melhor qualidade de vida (ALTMAN; REGO; ROSS, 2009; ANDERSON; BILLOU, 2007; NASCIMENTO; YU; SOBRAL, 2008; WOOD; PITTA; FRANZAK, 2008). Entretanto, poucos estudos foram encontrados dedicados a entender o lado oposto desse fenômeno, a insatisfação de consumidores de baixa renda.

Autores que exploraram o tema no Brasil (CHAUVEL, 2000; CHAUVEL; SUAREZ, 2009) mostram que, aos olhos de alguns consumidores de baixa renda, empresas são indiferentes às suas reclamações e exercem poder sobre eles. Essa visão leva tais indivíduos a terem ceticismo em 
relação às empresas e as possibilidades de sucesso em reclamar.

Segundo Fernandes e Santos (2007), há poucos estudos no Brasil que tratam da insatisfação e do comportamento de reclamação dos consumidores.

Isso é preocupante do ponto de vista de acadêmicos e praticantes brasileiros, pois a literatura predominante sobre o tema é em grande parte americana ou europeia; ambientes com características política, econômica, social e cultural distintas do Brasil. Esse quadro se faz ainda mais preocupante quando o foco do estudo é na insatisfação e no comportamento de reclamação de consumidores de baixa renda no Brasil, em função da escassez de estudos, tanto estrangeiros quanto brasileiros, sobre o tema (CHAUVEL; SUAREZ, 2009).

Diante dessa lacuna na literatura sobre insatisfação e comportamento de reclamação de consumidores de baixa renda, a presente pesquisa tem como objetivo estudar como consumidores desse segmento reagem quando em situações de insatisfação de consumo.

A estruturação do trabalho é dividida em mais quatro seções. Na segunda seção, as contribuições da literatura sobre insatisfação e comportamento de reclamação de consumidores de baixa renda são discutidas. Na terceira seção, o método como a pesquisa foi conduzida é descrito, dando ênfase à técnica de coleta de dados utilizada. Na quarta seção, os principais achados da pesquisa são discutidos, divididos em três subitens. Por fim, na quinta seção, as considerações finais da pesquisa são apresentadas.

\section{Insatisfação de Consumidores de Baixa Renda: contribuições da literatura}

O interesse da área de marketing, especialmente nos Estados Unidos, em estudar consumidores de baixa renda data desde os anos 1960 (RATNER, 1968; STURDIVANT; WILHELM, 1969; TOYER, 1968). Em função do movimento consumerista da época, estudiosos passaram a dar atenção à relação que esses indivíduos possuíam com o consumo. À medida que a agenda consumerista foi perdendo espaço para visões mais liberais de mercado (COHEN, 2003), estudos sobre consumidores de baixa renda também foram deixados em segundo plano (ANDREASEN, 1978). Embora alguns autores tenham continuado a estudar consumidores de baixa renda (ANDREASEN, 1993; MORGAN; SCHULER; STOLTMAN, 1995), pesquisas dessa natureza eram escassas.

Somente quando Prahalad, no início dos anos 2000, apontou para o fato de haver bilhões de consumidores na base da pirâmide, ávidos por consumir produtos de qualidade (PRAHALAD; HAMMOND, 2002; PRAHALAD; HART, 2002), é que a academia voltou a desprender maiores esforços para entender esse consumidor (PETRESCU; BHATLI, 2013; PINTO, 2013; PRADO; BRITO; SERRALVO; TOLEDO, 2014; ROCHA; ARAUJO; MOTTA, 2014). Segundo Prahalad (2006), ao invés de considerá-los pobres, empresas deveriam vê-los como consumidores em potencial, que, mesmo com parcos rendimentos, representavam, em conjunto, uma massa consumidora.

Apesar do recente interesse, grande parte da literatura que discute a base da pirâmide parte da perspectiva empresarial, mostrando quais são os caminhos que devem ser adotados para se garantir resultados positivos na comercialização para indivíduos desse segmento (BLOWFIELD, 2012; CRUZ, 2010; GUESALAGA; MARSHALL, 2008; ZILBER; SILVA, 2013). Dessa forma, mesmo que exista um aumento no número de estudos sobre a base da pirâmide, ainda se conhece pouco sobre o consumidor inserido nesse contexto (ROCHA; SILVA, 2009).

A falta de conhecimento sobre consumidores de baixa renda é ainda maior quando analisados a insatisfação de consumo e o comportamento de reclamação desses indivíduos. 0 que se discute, entretanto, e que justifica o melhor entendimento sobre esses fenômenos, é que consumidores de baixa renda apresentam formas diferentes de lidar com a insatisfação do que seus pares de 
renda mais elevada (ANDREASEN, 1993; FOX, 2008).

No estudo de Chauvel e Suarez (2009), por exemplo, é constatado que consumidores de baixa renda tendem a ter uma perspectiva passiva quanto a reclamar.

Diversos fatores explicam esse motivo. Segundo as autoras, seus entrevistados julgam ser difícil a decisão de se dirigir às empresas, com a intenção de expor sua insatisfação, e sentem ansiedade por ter que fazê-lo. Embora tal sensação também fosse constatada em consumidores de outras classes sociais, eram nas mais baixas que se percebia com maior presença.

Halstead, Jones e Cox (2007) mostram uma perspectiva diferente para o motivo de consumidores de baixa renda não reclamarem. Para os autores, esses indivíduos raramente entendem que podem ou têm direito de reclamar ou conhecem o procedimento correto para fazê-lo. Possivelmente, um dos motivos que contribui para essa passividade é a falta de educação formal desses indivíduos, o que dificulta o acesso a informações e gera vergonha em reclamar, devido à baixa capacidade de se comunicarem adequadamente.

Parente e Barki (2008) reforçam essa ideia quando dizem que consumidores de baixa renda tendem a ter baixa autoestima e escolaridade e que, por isso, valorizam quando um vendedor lhes dá uma explicação clara do que está sendo oferecido a eles. Entretanto, nem sempre há verdade em tudo o que o vendedor oferece ao consumidor. Patwardhan, Noble e Nishihara (2009) mostram em seu estudo que há empresas que treinam seus funcionários a enganarem consumidores, de forma a obterem sua colaboração e confiança. Knights, Sturdy e Morgan (1994) corroboram essa informação ao apontar que vendedores tendem a oferecer produtos e serviços que possuam maiores margens de lucros para as empresas, mesmo que esses não sejam os melhores para os clientes.

Em situações como essas, em que o consumidor se sente lesado, ele pode reclamar à empresa, a fim de obter alguma compensação por sua "perda". Entretanto, no caso de consumidores de baixa renda, a perspectiva de um possível conflito ser iniciado devido à reclamação os intimida, a ponto de optarem por não criar tais situações. Esse receio é tamanho que preferem não se queixar às empresas, mesmo que tenham sentimentos de perda bastante agudos, e assumem o prejuízo pela perda do bem comprado (CHAUVEL; SUAREZ, 2009).

0 silêncio de consumidores de baixa renda pode ser atribuído, em parte, à preocupação em sofrerem discriminação social (AGUIAR; TORRES; MEIRELES, 2008). Esses indivíduos acreditam ser tratados com menos respeito por comerciantes, em função de suas condições econômicas e sociais serem menos privilegiadas (PARENTE; BARKI, 2008). A falta de respeito a eles, em consequência, afeta negativamente seus níveis de satisfação (CHAUVEL, 2000; HALSTEAD; JONES; COX, 2007).

A sensação de que a reclamação não resultará em ganhos, e, por isso, não vale a pena reclamar, também pode ser explicada pelo receio de passar por "malandro", conforme explica Chauvel (2000). Consumidores de baixa renda temem que suas queixas sejam interpretadas como uma tentativa de "tirar vantagem" de alguma situação, pondo em questionamento sua honestidade. A autora analisa que os consumidores de classes mais elevadas também se preocupam com a legitimidade de suas queixas, mas atribuem o problema a uma falha do produto, e não do usuário. Os consumidores de classes mais baixas tendem a pensar de forma contrária, imaginando que eles podem ter cometido algum erro, o que, consequentemente, teria resultado na quebra do produto.

0 sentimento de inferioridade que consumidores de baixa renda têm em relação a empresas resulta em pensamentos céticos e de desconfiança (CHAUVEL; SUAREZ, 2009). De uma forma geral, esses indivíduos acreditam que empresas só querem vender e lucrar, não importando se seus clientes estão satisfeitos ou insatisfeitos. Tais pensamentos podem ser considerados um 
forte indicador de insatisfação, mas dificilmente se transformam em reclamações (HALSTEAD; JONES; COX, 2007).

FitzPatrick, Friend e Costley (2004) seguem essa linha de raciocínio, pois acreditam que a insatisfação dos consumidores está relacionada à forma como as organizações os vêem. Qualquer indivíduo que fuja a um padrão de "normalidade" - que pode ser considerado um arquétipo de um consumidor de classes mais elevadas - é visto com desconfiança.

Uma forma de fugir das descriminações que consumidores de baixa renda sofrem é comprando produtos de marcas conhecidamente superiores (CHAUVEL; MATTOS, 2008). Ao fazerem isso, esses indivíduos diferenciam- se dos "mais pobres ainda" e imaginam estar em vias de pertencer ao "mundo dos ricos" (BARROS, 2006a). A compra de produtos de marcas superiores traz para consumidores de baixa renda uma sensação de proteção contra possíveis riscos de serem enganados. Ao pagarem por uma marca superior, acreditam estar recebendo um produto de qualidade e, junto a isso, um atendimento justo e digno, semelhante ao que consumidores de classes mais elevadas recebem (BARKI; PORTO, 2008).

Conforme aponta a literatura, a relação entre consumidores de baixa renda e empresas é conflituosa. Esses indivíduos acreditam que se fossem de classes mais elevadas, teriam um tratamento melhor. 0 receio em ser descriminado devido à sua classe social e a falta de conhecimento sobre como reclamar resulta, em muitos casos, em passividade quando insatisfeitos com um produto ou um serviço. Consequentemente, teorizações que buscam explicar a insatisfação de consumo e o comportamento de reclamação precisam levar em consideração tais sentimentos, comuns no contexto de consumo na base da pirâmide.

\section{Método da Pesquisa}

No passado, autores brasileiros que estudaram o consumo nas camadas populares e/ou a insatisfação de consumidores de baixa renda utilizaram métodos qualitativos e quantitativos para conduzir suas pesquisas (BARROS; ROCHA, 2009; CASOTTI, 2004; CASTILHOS; ROSSI, 2009; CHAUVEL, 2000; CHAUVEL; SUAREZ, 2009; MATTOSO; ROCHA, 2008; PONCHIO; ARANHA, 2007; SILVA; PARENTE, 2007). Os estudos de natureza qualitativa, em geral, adotaram entrevistas em profundidade e técnicas de "inspiração" etnográficas como principais métodos para coletar dados. Já os de cunho quantitativo utilizaram, por exemplo, survey, para esse fim.

O método adotado para a coleta de dados, no presente estudo, difere de outros, pois utiliza a técnica projetiva. De acordo com Boddy (2005) técnicas dessa natureza são comumente utilizadas em pesquisas qualitativas, e seu uso em marketing pode ser visto em diversos estudos (HOFSTEDE et al., 2007; LEVY, 1994; MOUTINHO, DIONÍSIO e LEAL, 2007; PARSONS , 2002; PETTIGREW; CHARTERS, 2008). A técnica projetiva facilita a articulação de pensamentos reprimidos por parte do respondente, já que ele "projeta" seus pensamentos a alguém ou alguma coisa, ao invés de si mesmo (BODDY, 2005). Em vez de questionar um entrevistado sobre as suas opiniões a respeito de determinado assunto, esse método permite que perguntas sejam formuladas com base no que ele acha que outro indivíduo faria em determinada situação (ROOK, 2006). Assim, possibilita maior liberdade para o entrevistado responder o que realmente pensa, já que, a princípio, ele não está falando de si próprio (WILL; EADIE; MacASKILL, 1996).

A justificativa para a utilização dessa técnica no presente trabalho se deve às dificuldades em realizar pesquisas com consumidores de baixa renda, quando o pesquisador não pertence à realidade dos entrevistados. Há riscos de a presença de um entrevistador de outra classe inibir 
os participantes da pesquisa de contarem suas reais opiniões (CASOTTI; SUAREZ; DILEZA, 2009). Por meio da técnica projetiva, imagina-se que essa preocupação pode ser amenizada.

Entre as diversas técnicas projetivas utilizadas em marketing, tais como associação de palavras, testes com desenhos animados, exercícios de completar frases e personificação de objetos, a escolhida para esse estudo foi a de histórias temáticas, conforme denominação de Rook (2006). Nesta, é apresentada uma situação sem que o seu fim seja explicitado, e perguntado ao entrevistado como se desenvolveu a situação a partir daquele momento.

Em vista de o fenômeno analisado ser a insatisfação de consumo, foram criadas três situações de insatisfação com serviços de telecomunicações, planos de saúde e crediário. A escolha por limitar problemas de consumo a somente esses serviços ocorreu por dois motivos. Em vista de a técnica projetiva não demandar que os entrevistados tenham vivenciado o problema a eles apresentado (ROOK, 2006), a princípio seria possível criar situações de insatisfação tanto com produtos quanto com serviços, ou, até, com ambos. Porém, preferiu-se focar somente em um dos dois para que os sentimentos e comportamentos relatados fossem mais facilmente comparados. Aliado a isso, entre todas as reclamações registradas junto ao SINDEC, em anos recentes, as relativas aos serviços de telecomunicações, planos de saúde e financeiros são as que possuem maior índice.

As situações de insatisfação apresentadas para os entrevistados foram três, uma para cada um dos serviços de telecomunicações, planos de saúde e crediário, e descritas da seguinte forma:

- Situação 1: José/Mônica comprou um cartão de R \$15 para colocar créditos em seu celular. Quando ele/ela raspou o cartão, rasgou o código que precisaria para ter direito aos créditos.

- Situação 2: Mario/Maria foi a um médico para fazer uma consulta, pois estava com dores no estômago. 0 médico pediu que ele/ela fizesse alguns exames, mas, primeiro, Mario/Maria precisaria pedir autorização ao seu plano de saúde para fazê-los. Quando ele/ela foi pedir a autorização, o plano de saúde negou o seu pedido.

- Situação 3: Antônio Carlos/Ana Claudia comprou uma televisão e contratou um crediário para poder pagá-la em 12 parcelas. Ele/ela sempre pagava as parcelas em dia, mas quando chegou a data da oitava parcela, Antônio Carlos/Ana Claudia se esqueceu de pagá-la. Oito dias depois, Antônio Carlos/Ana Claudia recebeu uma carta dizendo que o seu nome havia sido colocado no SPC (Serviço de Proteção ao Crédito), sem ter sido avisado que a empresa do crediário iria fazer isso.

Foi feito um pré-teste com quatro consumidores de baixa renda (dois homens e duas mulheres), a fim de verificar dificuldades de entendimento ou se havia palavras que não eram compreendidas pelos entrevistados. Casotti, Suarez e Deliza (2009) relatam que o uso de palavras formais ou complicadas pode criar dificuldades no momento de entrevistar consumidores de baixa renda.

Durante a análise dos dados do pré-teste, percebeu-se que os entrevistados davam respostas menos estruturadas quando o nome do consumidor protagonista da situação descrita era do gênero oposto ao dele. Provavelmente, isso ocorria porque era mais difícil para os entrevistados se projetarem como um indivíduo do outro gênero. Assim, para corrigir esse problema, foi dado um nome masculino e um feminino para os protagonistas das situações de insatisfação. Dessa forma, quando um homem era entrevistado, utilizava-se o nome masculino do protagonista, e, da mesma forma, quando uma mulher era entrevistada, o nome dado ao protagonista era feminino. 
Pelo fato de a técnica projetiva buscar impressões emocionais e significativas sobre um episódio que possa ocorrer com um consumidor, não é necessário que ele a tenha vivenciado para que as informações coletadas sejam válidas para o propósito da pesquisa (R00K, 2006).

No início de todas as entrevistas, enfatizava-se esse fato aos participantes, de forma a garantir que todos expressassem opiniões sobre as situações descritas.

Para garantir que os entrevistados fossem consumidores de baixa renda, utilizou-se o Critério de Classificação Econômica do Brasil, também chamado de Critério Brasil, que estima o poder de compra dos indivíduos e famílias urbanas, com base no Levantamento Socioeconômico do IBOPE (ABEP, 2008). De acordo com Barros (2006b), com base no Critério Brasil, o consumidor de baixa renda seria aquele pertencente às classes C, D e E. Limeira (2008) também considera que consumidores de baixa renda são aqueles pertencentes às classes $C, D$ e $E$, porém a classificação em que se baseia é a do Instituto Brasileiro de Geografia e Estatística (IBGE), cujo critério para definir em qual classe um indivíduo se encontra é a renda familiar mensal.

Durante as entrevistas, o pesquisador lia para o entrevistado as situações de insatisfação com serviços e anotava o que era respondido. Garantia-se, dessa forma, que o participante da pesquisa não ficaria intimidado por precisar escrever suas respostas, já que é comum o baixo nível de escolaridade em consumidores de baixa renda (PARENTE; BARKI, 2008), o que poderia dificultar a obtenção de respostas.

Ao todo, foram entrevistados 28 consumidores de baixa renda. Desse total, 17 eram mulheres e 11, homens. Embora diversos fossem trabalhadores formais, empregados como porteiros, office boys, empregadas domésticas e secretárias, havia um grupo de entrevistados que estava desempregado no momento das entrevistas. Para sobreviver, realizavam "bicos", vendendo produtos, tais como balas, que compravam em depósitos comerciais ou trabalhavam como faxineiras ou babás, quando surgiam oportunidades. As idades dos participantes da pesquisa variavam de 19 a 62 anos, e nenhum possuía ensino superior completo, embora três entrevistados estivessem matriculados em universidades, à época das entrevistas.

Por meio de técnica de bola de neve, um grupo inicial de entrevistados indicou outros para participarem da pesquisa. As entrevistas foram realizadas nas residências ou locais de trabalho dos entrevistados, definidos conforme sua preferência. 0 número final de entrevistados foi definido quando foi atingida saturação de dados, momento este em que as entrevistas passaram a não mais acrescentar novos códigos durante a análise dos dados, conforme indicam Guest, Bunce e Johnson (2006).

Todas as entrevistas foram transcritas, para que a análise dos dados, dividida em duas partes, pudesse ser feita. Em um primeiro momento, foram lidas todas as transcrições das entrevistas, a fim de codificar os achados. Esse processo de análise se caracteriza por ser uma comparação entre os dados de todas as entrevistas, para que códigos (referentes a temas importantes achados durante a análise) sejam criados (SPIGGLE, 1994). A leitura das entrevistas foi feita repetidas vezes, a fim de garantir que os dados analisados fossem codificados corretamente. Em um segundo momento, utilizou-se da técnica de análise de discurso, seguindo orientações de Gill (2002) e Rubin e Rubin (2005), para analisar os dados da pesquisa, a partir dos códigos criados anteriormente.

\section{Achados da Pesquisa}

Durante o processo de análise dos dados, percebeu-se que há duas perspectivas a respeito do que o consumidor deve fazer diante de situações de insatisfação. A primeira ilustra consumidores com uma atitude passiva sobre as ações que devem adotar para resolver seu problema. Eles evitam o conflito direto com empresas e mostram-se conformados com a 
situação, de forma que o continuem prejudicados. A segunda, diferentemente, ilustra uma reação do consumidor contra a situação de insatisfação em que se encontra.

Nessa perspectiva, ele reclama às empresas e, até, pode exercer seus direitos por meio de medidas legais. As duas perspectivas permeiam os relatos dos entrevistados quando falam como se sentem diante das situações de insatisfação descritas.

Como o objeto do estudo foi a insatisfação de consumo, além dessas duas perspectivas, foi possível identificar também nos relatos reações sentimentais diante das situações que lhes eram apresentados. Em muitos casos, tais sentimentos foram resultantes da percepção sobre a quem recaía a culpa pelo ocorrido: as empresas que venderam serviços deficitários ou os consumidores que não sabem usar os serviços adequadamente.

Diante desses padrões de respostas encontrados, decidiu-se dividir a análise em três categorias: comportamentos passivos diante da situação de insatisfação; comportamentos reativos diante da situação de insatisfação; e sentimentos despertados a partir da situação de insatisfação.

\section{Comportamentos passivos diante da situação de insatisfação}

Quando solicitados a analisar as situações de insatisfação, um grupo de entrevistados mostrou propensão a acreditar que o consumidor está em uma posição de inferioridade em sua relação com as empresas. Dessa forma, descrevem comportamentos passivos e conformados com a situação de insatisfação. As sugestões de solução para as situações mostram tentativas de contornar o problema sem envolver a empresa de serviços.

A posição passiva e que assume a inferioridade do consumidor diante das empresas foi vista, especialmente, quando a situação de insatisfação descrita era com o plano de saúde. Essa foi a que gerou as respostas mais claras e expressivas sobre um comportamento do consumidor que não se move para reclamar com as empresas e procurar soluções para o problema em algum canal de comunicação disponibilizado pela empresa, conforme pode ser visto nos diferentes relatos:

Deveria procurar o SUS (Sistema Único de Saúde), ou um médico que não fosse tão bom, ou a Santa Casa.

Deveria conversar com o médico para saber a real importância do exame.

Voltou para casa.

Dependendo do preço do exame e da gravidade da doença, ou esqueceria do exame ou tentaria pagá-lo.

Se não tiver dinheiro, com certeza irá deixar de ir (fazer o exame), e procuraria alguma farmácia para comprar um remédio escolhido pelo farmacêutico, para amenizar a dor, e esperar passar.

Esse comportamento passivo também foi apontado no estudo de Chauvel e Suarez (2009), quando consumidores de baixa renda deixavam de reclamar suas insatisfações, a fim de evitar conflitos com as empresas, e acabavam até assumindo o prejuízo pela perda do bem comprado. A diferença entre os depoimentos coletados pelas autoras e os encontrados nessa pesquisa é que a submissão nos relatos acima não traz sentimentos de frustração, tristeza e raiva, mas de conformismo diante de uma situação que poderia ter conseqüências mais sérias como prejudicar a saúde, já que deixariam de fazer o exame necessário.

Alguns entrevistados mostram reações negativas, por acreditarem que tais organizações não têm escrúpulos. Para esses indivíduos, a empresa "só quer ganhar dinheiro", "não respeita seus clientes" e tornam os consumidores "reféns" de suas políticas. Mas essas reações não parecem suficientes para tirá-los de uma posição de passividade. As explicações para isso passam por sua condição de classe econômica. Acreditam que empresas tratam consumidores de baixa renda 
com menos respeito, pois "se tivesse dinheiro, não estaria passando por isso" esclarece um dos entrevistados.

Tais relatos vão ao encontro do que também acreditam os entrevistados de outros estudos (CHAUVEL; SUAREZ, 2009; HALSTEAD; JONES; COX, 2007), de que as empresas tratam com menos respeito devido à sua condição sócio-econômica.

Mesmo reconhecendo a situação de consumidores insatisfeitos, alguns entrevistados não acreditam que reclamações trariam benefícios, pois, para eles, não há "muito o que fazer". Embora lamentem as perdas, aceitam a condição de inferioridade quando atribuem a culpa pelas situações descritas como sendo predominantemente do consumidor, como se ele estivesse sendo castigado por um erro por ele provocado, ou seja, sua insatisfação, assim, seria merecida. Em seus depoimentos, não demonstram sequer considerar a possibilidade de as empresas terem parcela de culpa pelo acontecido ou que tenham que oferecer outra solução para o problema. Como reclamar ou demonstrar a insatisfação junto às empresas se acreditam que erraram? Os relatos a seguir mostram como a "culpa" ou "erro" são atribuídos preferencialmente aos consumidores:

\footnotetext{
Eu não faria nada, o erro é meu, apenas compraria outro.

Ana Claudia (protagonista da situação de insatisfação) foi até a loja que fez o crediário para pagar o carnê em atraso, e não questionou o envio de seu nome ao SCP, já que o erro foi seu.

Compraria outro (cartão de recarga de celular), pois eu mesmo fui o culpado.

Jogaria o cartão (de recarga de celular) fora, pois ela é culpada, e como punição nem deve tentar trocar na loja.

A gente (consumidores de baixa renda) não tem direito a muita coisa.
}

Essas constatações também são encontradas no estudo de Chauvel (2000). A autora aponta que consumidores de baixa renda tendem a acreditar que eles são os culpados pela quebra dos produtos em sua posse e, por isso, não tentam reclamar com as empresas, pois não têm razão em fazê-lo.

\section{Comportamentos reativos diante da situação de insatisfação}

Um segundo grupo de entrevistados mostrou um comportamento diferente sobre a forma como o consumidor deve se posicionar diante das situações de insatisfação descritas. Esses indivíduos acreditam que estão em seu direito reagir, seja reclamando com as empresas ou tomando medidas legais, para não ficarem em desvantagem.

Mesmo sendo um grupo de entrevistados de classe popular, mostra uma confiança maior em suas sugestões sobre a forma como consumidores devem lidar com empresas em situações de insatisfação. Relatos de passividade ou sentimentos de inferioridade são substituídos por relatos conscientes do que acreditam precisar ser feito para que o problema seja resolvido, 0 que muitas vezes inclui reclamar diretamente com a empresa. Uma das formas para se efetuar a reclamação, citado por um dos entrevistados, é no mínimo curioso, já que ainda imagina ser a carta, ao invés da internet, o meio de comunicação mais adequado para tal situação. Os depoimentos a seguir demonstram essas perspectivas:

\footnotetext{
Buscou explicação com o plano de saúde.

Tentaria trocar o cartão (de recarga do celular) no lugar que comprou.

Monica (protagonista da situação de insatisfação) entrou em contato com a operada e usou o código (de barra do cartão de recarga do celular). Monica não poderia sair no prejuízo.

Mandou uma carta para o crediário.
}

Embora alguns entrevistados demonstrem acreditar que reclamações do consumidor estão 
apoiadas em seus direitos legais, parecem não saber ao certo quais são.

Dessa forma, essa crença parece ser colocada em dúvida quando utilizam expressões como "esperança": "o consumidor deve se dirigir à empresa com a esperança de conseguir trocar por outro (cartão de recarga de celular)”, descreveu um dos entrevistados.

Outro aspecto que sugere o não conhecimento em relação aos direitos que possuem são os relatos que descrevem o uso da informalidade para resolver problemas. Em vez de buscarem seus direitos legais para enfrentar as empresas, alguns entrevistados sugerem a "camaradagem" do vendedor ou atendente, para resolver o problema ou mesmo alegam que o consumidor deveria "implorar para o moço" (referindo-se ao atendente do plano de saúde) "tentar dar um jeito" e "explicaria o que ocorreu, para conseguir uma solução". Assim, essas descrições indicam que os consumidores buscam, antes de seus direitos, a informalidade, pois acreditam ser a maneira mais fácil ou rápida para resolver problemas. Essa prática foi definida por Barbosa (1992) como "jeitinho brasileiro"; um comportamento criativo para superar situações adversas, sem contestar ou recusar a lei, que dependem da habilidade do interlocutor de envolver emocionalmente aquele que o ouve.

Motta e Alcadipani (1999) mostram como a cultura da pessoalidade é valorizada no Brasil. Quando uma pessoa conhece alguém com poder ou tem um "padrinho", como se fala na linguagem popular, suas vontades individuais podem ser favorecidas dentro do contexto do coletivo. 0 "jeitinho" ocorre quando há uma reinterpretação da determinação que impossibilita a ação pretendida, de forma a permitir que a exceção seja aceita, ou seja, é uma forma de “"burlar" determinações que, se levadas em conta, inviabilizariam ou tornariam difícil a ação pretendida pela pessoa que pede o jeito" (p.9).

Porém, o que se argumenta aqui é que esses entrevistados parecem sugerir o uso do "jeitinho" para resolver um problema que não necessariamente precisaria ser resolvido dessa forma. Mas, a falta de conhecimento quanto ao que podem e não podem fazer, e também das possibilidades de canais de comunicação com as empresas, leva alguns entrevistados, em suas descrições projetivas, a sugerirem um caminho para que o consumidor tente resolver o problema na base do improviso, e que pode estar sujeito, por exemplo, à bondade de quem o atender.

Um dos entrevistados, no entanto, reconhece que o consumidor de baixa renda é uma "vítima da desinformação". Em alguns depoimentos que defendem um consumidor mais pró-ativo em suas reclamações com as empresas, os problemas são atribuídos a detalhes da parte tangível do serviço, e não devido a uma falha no processo do serviço oferecido pela empresa. No caso da situação de insatisfação com o cartão de recarga de celular, por exemplo, alguns entrevistados alegam que o consumidor deveria reclamar porque "a qualidade (do cartão) deveria ser melhor", e que "se o cartão rasgou é porque não é muito bem feito", ou seja, o problema tem um foco específico que parece proteger a empresa prestadora do serviço.

Halstead, Jones e Cox (2007) apontam em seu estudo que consumidores de baixa renda tendem a não conseguir fazer uma avaliação global de satisfação. 0 julgamento que fazem do desempenho de um produto ou serviço é formado a partir de detalhes, que determinam se suas necessidades foram ou não atendidas. Assim, se algum incidente insatisfatório com o desempenho de algum produto ou serviço ocorrer, mesmo que seja pela primeira vez, é a lembrança recente que forma a insatisfação.

Curiosamente, relatos desse grupo de entrevistados mostram como é importante a busca de apoio de outra pessoa no momento em que o consumidor vai reclamar. Dois participantes da pesquisa apontaram que o protagonista da situação de insatisfação deveria pedir ajuda "para 
sua patroa" ou "para um amigo".

Em vista de consumidores de baixa renda comumente desconhecerem a maneira e os meios corretos para se reclamar (HALSTEAD, JONES e COX, 2007), essa "ajuda" parece reconhecer a classe mais alta - a patroa -possivelmente mais capacitada ou com acesso mais facilitado para buscar a resolução do problema.

Alguns entrevistados que demonstraram mais pró-atividade em relação às situações de insatisfação falaram da busca de ajuda legal, para ter seu direito atendido. Eles são favoráveis ao uso de instituições de defesa do consumidor, tais como o Procon, o que demonstra duas possíveis situações: ou possuem consciência sobre como usar meios públicos para garantir o respaldo dos direitos do consumidor ou simplesmente dizem que se deve "processar a empresa", como se tal ação fosse fácil de fazer. Questiona-se se os indivíduos do segundo grupo estariam realmente dispostos a abrir um processo contra empresas, e conviver com a indefinição durante seu decorrer, ou se usam dessa retórica como uma ameaça, semelhante ao "você sabe com quem está falando?" de Da Matta (1988).

\section{Sentimentos despertados a partir da situação de insatisfação}

De uma forma geral, quando os entrevistados foram perguntados sobre como o consumidor se sentiu diante da situação de insatisfação, suas respostas remetiam a reações fortes e de cunho negativo: "indignada", "injustiçada", "lesada", "arrasada", "desrespeitada", "aborrecido", "enfurecido", "revoltado", "frustrado", "estressada", "muita raiva", "impotente", "angustiada" e "sentiu como se tivesse rasgado R \$15 (valor do cartão de recarga do celular)".

Para alguns entrevistados, a insatisfação é retratada como um sentimento forte, que reflete não apenas o que o personagem da situação descrita na técnica projetiva poderia estar sentindo, mas as reações que o próprio entrevistado imagina que teria ou sentiria: "uma burra" ou "mais um qualquer no mundo". Esses depoimentos sugerem que a decepção com a falha dos serviços é tamanha que passa a ser vista como uma afronta direta ao consumidor, como se o problema fosse criado de propósito para afetá-lo pessoalmente, ignorando completamente qualquer tipo de sentimento dos consumidores. Uma entrevistada, inclusive, relatou que a consumidor deveria "mudar de plano para um que fosse mais sensível a seus problemas".

Chauvel e Suarez (2009) argumentam que consumidores de baixa renda tentam se proteger contra eventuais falhas de bens e serviços comprando produtos de marcas conhecidas, com melhor qualidade. Entretanto, quando falhas ocorrem, suas reações vão "muito além de uma simples decepção" (Ibidem, p.198), pois, além de enganados, acreditam que também foram discriminados.

Em consequência dos sentimentos negativos, alguns entrevistados relatam que as frustrações do consumidor devem ser externalizadas agressivamente; inclusive, com o objetivo de prejudicar a imagem da empresa que proporcionou a insatisfação, conforme apontam os seguintes depoimentos:

Xingou meio mundo; perdeu R $\$ 15$ (valor do cartão de recarga do celular).

Fez um escândalo.

Ele ficou enfurecido, espalhou para todos que conhecia, inclusive no Orkut e no jornal 0 Globo, na coluna de defesa do consumidor, no intuito de avisar as pessoas da falta de seriedade da empresa que o colocou no SPC.

Rose e Neidermeyer (1999) acreditam que sentimentos de raiva estão associados à percepção 
do consumidor de que foi mal atendido. Portanto, quando isso ocorre, reagem de forma agressiva, para desencorajar empresas de continuarem a fazer o que ocasionou a raiva e, também, remediarem a falha (BOUGIE; PIETERS; ZEELENBERG, 2003).

0 estudo de Funches (2008) mostra que os motivos que mais enfurecem consumidores quando adquirem bens e serviços são as promessas não cumpridas e a deslealdade na forma como são tratados por empresa ou funcionários.

Uma explicação para as fortes reações que os entrevistados relatam sobre as situações de insatisfação pode estar relacionada ao receio que possuem de serem vistos como indivíduos sem dignidade. Chauvel (2000) aponta que consumidores de baixa renda temem que suas reclamações sejam interpretadas como uma tentativa de "tirar proveito" da situação, pondo em dúvida a sua honestidade. Essa visão pode ser vista nos seguintes relatos:

Correu para pagar a prestação e tirar o seu nome do SPC.

Sentiu-se mal por ter ido para no SPC, pois sempre pagou em dia.

Com medo de perder a sua credibilidade.

Deveria enviar o cartão para a operadora para mostrar o ocorrido.

Sujaram o seu nome indevidamente (com relação ao consumidor ter o seu nome inserido no SPC).

A preocupação em manter a dignidade e ser percebido por outros como um indivíduo honesto foi observada de forma recorrente. Para os entrevistados, os bens que o consumidor possui são adquiridos com "sacrifício", e esse esforço não deve ser desmerecido por ninguém. Como uma entrevistada disse: "não passo a perna em ninguém e não gosto que passem a perna em mim".

Miller (2002) aponta que existe uma relação íntima entre sacrifício e consumo, que vincula-se, em diversos casos, a um poder transcendental, divino. Ao consumir um objeto que demanda sacrifício, o indivíduo busca algo superior - descrito pelo autor como "meta transcendental" -, e abre mão das preocupações associadas às consequências profanas e sociais inerentes a este ato. Embora o consumo seja descrito como um dispêndio dos recursos acumulados por meio do trabalho, Miller também o associa ao ato de abastecimento, em que consumir é uma forma de manutenção do bem estar coletivo, do lar e da família.

A descrição do sacrifício ou de esforço que permeia suas vidas aparece também nas associações que fazem do consumo com o trabalho como se fossem dois lados de uma mesma moeda ou de um mesmo sacrifício, pois misturam o esforço para consumir com o esforço para trabalhar quando, por exemplo, descrevem que aquele consumidor da situação de insatisfação com o consumo "pega em média três conduções para trabalhar". Mas o trabalho parece exprimir outra lógica que o relaciona também com honestidade: "ele é trabalhador, não ia querer tirar proveito de nada" o que parece sugerir uma relação entre trabalho, consumo e honestidade para as camadas mais populares que talvez não pudessem ser observadas em camadas mais afluentes da população.

De acordo com Rocha (2005), a condição de ser um trabalhador e estar em condições de produzir é uma legitimação do caráter do indivíduo. Para o autor, "classificar alguém como bom trabalhador, produtivo, dedicado à empresa (ou até mesmo workaholic) é atribuir uma identidade positiva" (p.129 - itálicos do original). Dessa forma, o homem que trabalha, que produz, está realizando algo nobre, valoroso e engrandecedor, já que a vida é "levada a sério".

Gini (1998) complementa essa visão quando expressa que trabalho não é simplesmente a troca de esforço por dinheiro: é necessário trabalhar para que se possa encontrar uma identidade, formar caráter, e poder ser identificado pelo trabalho que se faz. Watarai e Romanelli (2005) observam que o ingresso no mercado de trabalho, seja no formal ou no informal, transforma a 
vida de adolescentes de camadas populares da sociedade. Esses jovens assumem um novo papel diante de suas famílias, já que, em vez de apenas consumidores, passam a ser produtores de rendimentos. Tais mudanças afetam a identidade dos adolescentes, pois passam a ter autonomia e independência financeira, conquistados pelo fato de estarem trabalhando.

0 presente estudo buscou entender, também, como os entrevistados imaginam e descrevem os consumidores das situações hipotéticas de insatisfação colocadas pela pesquisa. As descrições muito espontâneas parecem refletir de fato personagens próximos da realidade dos entrevistados, o que sugere que a técnica projetiva funcionou como esperado.

O consumidor ou consumidora, na visão dos entrevistados, tem profissão: "empregada doméstica", "porteiro", "gerente de lan house", "vive de bicos", tem família: "tem dois filhos", "a esposa trabalha e cuida dos filhos", "é uma mãe de família", tem localidade: "mora em Realengo" tem ambições "é uma mulher batalhadora e com sonhos", e também pode ter cor "pardo" e religião "evangélico". Em alguns casos, as descrições parecem refletir as características do próprio entrevistado como, por exemplo, descrever o consumidor como "barbudo", "desempregado" ou precisando "ligar para o namorado para resolver um problema".

Um depoimento, em específico, chamou a atenção pela riqueza de detalhes e sentimentos com que descreveu o consumidor, ou melhor, com que contou a história de vida daquele personagem, deixando os pesquisadores em dúvida sobre o quanto aquela ficção estaria misturada ou não com a realidade do próprio entrevistado. Afinal era apenas um caso de insatisfação com o prestador de serviços que passava a ter um inesperado enredo.

Foi preso injustamente quando era menor (12 anos). Ele trabalhava como "boleiro" no clube (dos) Caiçaras. O dinheiro que tinha $(\mathrm{R} \$ 600,00)$ era o pagamento da quinzena. Ele tinha sido identificado por uma vítima de assalto por engano. 0 policial levou o seu dinheiro e celular. Ele foi para o Reformatório Padre Severino, (onde) apanhava todo dia. Quando foi solto, informou que tinha $R \$ 600,00$, e por isso teve a sua família ameaçada de morte pelo policial que "surrupiou a sua grana". Por isso, se tornou um jovem recolhido. Quando fez 16 anos, largou um emprego de garçom e aceitou o convite do chefe do tráfico para ser "olheiro", e ganhar $\mathrm{R} \$ 600,00$. Atualmente, mora na zona rural, tem sete irmãos. 0 pai é desempregado, vive bêbado, e sua mãe trabalha em uma creche. Ele queria entrar na faculdade, mesmo que fosse a Estácio (de Sá) ou Univercidade. Trabalha como porteiro na Zona Sul. É de cor parda, evangélico e acha que um dia vai sair dessa miséria, de forma honesta, apesar de já ter sido convidado pelo tráfico.

\section{Considerações Finais}

0 presente trabalho buscou conhecer melhor como consumidores de baixa renda reagem quando em situações de insatisfação de consumo. A partir de uma pesquisa de campo, diferentes implicações para os meios acadêmico e empresarial podem ser apontadas.

A literatura sobre consumidores de baixa renda, tanto no Brasil quanto no exterior, retrata que esses indivíduos possuem um comportamento diferente de consumidores de classes mais elevadas quando em situações de insatisfação. É comum essa literatura descrever que indivíduos na base da pirâmide abstêm-se de reclamar com empresas, pois acreditam que isso pouco lhes trará benefícios, já que suas reclamações não serão ouvidas.

Os achados da presente pesquisa, entretanto, mostram que essa realidade pode estar mudando, pelo menos no contexto estudado. Embora um grupo de entrevistados continue apresentando comportamentos passivos quanto à reclamação, outro demonstra consciência de que pode (e deve) reclamar quando percebe que houve um problema de consumo. Suas ações lembram a de consumidores de classes econômicas mais elevadas, pois "lutam" por seus direitos. 
Comumente, imaginar-se-ia que a ação de reclamar fosse dirigida à empresa causadora do problema, porém, esse é somente um dos caminhos a percorrer para solucionar a falha do serviço. Caso necessário, esse grupo de consumidores de baixa renda admite, inclusive, buscar ajuda legal de órgãos de defesa do consumidor, tais como o Procon, quando percebem que a empresa não foi solícita a suas reclamações.

Isso significa que demonstram conhecer, pelo menos em teoria, que há outros meios para se defenderem, que podem ser mais efetivos em reverter a situação problemática de consumo do que suas próprias reclamações.

Pode-se questionar até que ponto os relatos colhidos representam comportamentos que os entrevistados adotariam em casos reais, já que as situações de insatisfação de consumo apresentadas foram somente projeções. Acredita-se, entretanto, que essa possibilidade é real. Em nenhum momento da entrevista, quando eram contadas as situações aos entrevistados, foi descrito um perfil do consumidor insatisfeito ou foi apontado ou insinuado algo que fornecesse alguma pista sobre características do consumidor. Quem assumiu a perspectiva do personagem foram os entrevistados, que trouxeram comentários, observações, caracterizações que não colocavam em dúvida que estavam falando de alguém próximo de seus cotidianos. Isso sugere, então, que os relatos foram projeções sobre como eles de fato acreditam ser o comportamento de um consumidor das camadas populares, diante de situações de insatisfação com prestadores de serviços.

A escolha por usar a técnica projetiva esteve relacionada, principalmente, ao desconhecimento dos pesquisadores em relação às lógicas existentes nos comportamentos de consumidores de baixa renda diante de situações de insatisfação. A técnica, capaz de provocá-los a falar de forma mais livre, parecia ser capaz de ajudar a contribuir para a construção de um conhecimento ainda insipiente sobre o consumidor de serviços de classes de baixa renda.

Uma das dúvidas iniciais dos pesquisadores, inclusive, referia-se ao fato de os entrevistadores terem aparência, postura e linguagem identificadas com uma classe econômica distinta daquela dos entrevistados, o que poderia confundir ou inibir os entrevistados. Pelos achados analisados é possível sugerir que isso não ocorreu. As situações descritas funcionaram como um descolamento, não para a realidade do entrevistador, mas para a do entrevistado.

Cabe, nesse momento, chamar a atenção de empresas para a necessidade de compreender a diversidade de reações de consumidores de baixa renda em situações de insatisfação, o que é um desafio para as constantes tentativas de empresas prestadoras de serviços de padronizar seus processos, inclusive a etapa de atendimento. A racionalidade de que esses consumidores abrem mão de um atendimento de qualidade, por valorizarem mais preços baixos, parece não ser uma realidade.

Empresas prestadoras de serviços devem atentar não apenas ao comportamento relatado por esses entrevistados sobre esses personagens insatisfeitos, mas, também, a outros sinais de mudança no ambiente em que elas - as empresas - se encontram, já que representam mudanças nos comportamentos dos próprios consumidores de baixa renda, tais como:

1) 0 crescente conhecimento desses indivíduos sobre as possibilidades legais para apoiar suas insatisfações, por meio do Código de Defesa do Consumidor e/ou instituições de defesa do consumidor, tais como o PROCON, que tem registrado aumentos de reclamações nos últimos anos. Considerando que, entre os anos de 2002 e 2012, 37 milhões de brasileiros saíram das classes D e E, e foram inseridos na classe C, que, em 2012, representava 53\% da população brasileira (SECRETARIA DE ASSUNTOS ESTRATÉGICOS, 2012), tais fatos podem ter reflexo no crescimento do número de reclamações nesta instituição.

2) 0 crescente número de consumidores usando a internet para expor publicamente suas 
insatisfações (NASIR, 2004), por meio de redes sociais e/ou de fóruns específicos de reclamações on-line. Os relatos sugerem que os tradicionais canais de comunicação disponibilizados pelas empresas já não mais se enquadram como meios adequados para expor reclamações. Há desconfiança quanto a estes e sua verdadeira eficiência em auxiliar no processo de recuperação de falhas.

3) A influência que o comportamento de consumidores das classes A e B têm sobre a forma como consumidores da classe $C$ percebem seus direitos, visto que esse segmento passou a ser considerado a nova classe média brasileira (NERI, 2008), devido ao aumento de seus rendimentos e o poder de compras, desde a criação do Plano Real.

Mesmo com os achados dessa pesquisa, mais estudos sobre o consumidor de baixa renda, sua insatisfação e consequente reação precisam ser desenvolvidos. A base da pirâmide é descrita como uma grande oportunidade de negócios para empresas. Porém, comprovação de que tal afirmação é coerente somente ocorrerá quando houver um entendimento mais profundo sobre as particularidades de indivíduos desse segmento.

\section{Referências}

ABEP, Critério Brasil 2008. Disponível em: <http://www.abep.org/codigosguias/Criterio Brasil_2008.pdf>. Acesso em: 14 ago. 2009.

AGUIAR, L.; TORRES, H.; MEIRELES, R. 0 consumidor de baixa renda. In: PARENTE, J.; LIMEIRA, T.; BARKI, E. Varejo para a baixa renda, Porto Alegre: Bookman, 2008.

ALTMAN, D.; REGO, L.; ROSS, P. Expanding opportunity at the base of the pyramid. People \& Strategy, v. 32, n. 2, p. 46-51, 2009.

ANDERSON, J.; BILLOU, N. Serving the world's poor: innovation at the base of the economic pyramid. Journal of Business Strategy, v.28, n.2, p.14-21, 2007.

ANDRADE, D.; BALASSIANO, M.; BRANDÃO, M. Modelo estrutural do comportamento de retaliação e vingança do consumidor insatisfeito. Revista Brasileira de Marketing, v.12, n.1, p.51-72, 2013.

ANDREASEN, A. The ghetto marketing life cycle: a case of underachievement. Journal of Marketing Research, v.15, n.1, p.20-28, 1978.

ANDREASEN, A. Consumer satisfaction in loose monopolies: the case of medical care. Journal of Public Policy and Marketing, v. 2, n. 2, p. 122-135, 1984.

ANDREASEN, A. Revisiting the disadvantaged: old lessons and new problems. Journal of Public Policy \& Marketing, v. 12, n. 2, p. 270-275, 1993.

BARBOSA, L. O Jeitinho brasileiro: a arte de ser mais igual que os outros. Rio de Janeiro: Campus, 1992.

BARKI, E.; PORTO, R. Estratégia de produtos. In: PARENTE, J.; LIMEIRA, T.; BARKI, E. Varejo para a baixa renda. Porto Alegre: Bookman, 2008.

BARROS, C. Consumo, hierarquia e mediação: um estudo antropológico no universo das empregadas domésticas. In: ENCONTRO ANUAL DA ANPAD, 30., 2006, Salvador. Anais... Salvador: ANPAD, 2006a.

BARROS, C. A "invisibilidade" do Mercado de baixa renda nas pesquisas de marketing. In: ENCONTRO DE MARKETING DA ANPAD, 2., 2006, Rio de Janeiro. Anais... Rio de Janeiro: ANPAD, 2006b. 
BARROS, C.; ROCHA, E. Lógica de consumo em um grupo das camadas populares: uma visão antropológica de significados culturais in: ROCHA, A.; SILVA, J. (Org.) Consumo na base da pirâmide: estudos brasileiros. Rio de Janeiro: Mauad X, 2009.

BEBER, S; ROSSI, C. A. Estudo da insatisfação do consumidor nos serviços prestados por assistências técnicas autorizadas de automóveis. Revista de Administração Contemporânea, v.10, n.2, p.33-49, 2006.

BLOWFIELD, M. Business and development: making sense of business as a development agent. Corporate Governance, v.12, n.4, p.414-426, 2012.

BODDY, C. Projective techniques in market research: valueless subjectivity or insightful reality? A look at the evidence for the usefulness, reliability and validity of projective techniques in market research. International Journal of Market Research, v. 47, n. 3, p. 239-254, 2005.

BOLETIM SINDEC 2011. Brasília. 13 de janeiro de 2012. Disponível em: <http://portal.mj.gov.br/main.asp?ViewID=\{08DEBD27-66DA-4035-BE88-

27126C102E22 $\}$ \&params $=$ itemID $=\{$ F566866F-70C8-4AA4-91D9-

BB30B59D3AE7 $\} ; \& U I P a r t U I D=\{2218 F A F 9-5230-431 C-A 9 E 3-E 780 D 3 E 67 D F E ~\}>$. Acesso em: 13 set. 2012.

BOUGIE, R.; PIETERS, R.; ZEELENBERG, M. Angry customers don't come back, they get back: the experience and behavioral implications of anger and dissatisfaction with services. Academy of Marketing Science, v. 31, n. 4, p. 377-393, 2003.

CASOTTI, L. He who eats alone will die alone? An exploratory study of the meanings of the food celebration. Latin American Business Review, v. 6, n. 4, p. 69-84, 2004.

CASOTTI, L.; SUAREZ, M.; DILEZA, R. Consumo de alimentos nas famílias de baixa renda: compartilhando achados, experiências e aprendizados. In: ROCHA, A.; SILVA, J. (Org.) Consumo na base da pirâmide: estudos brasileiros. Rio de Janeiro: Mauad X, 2009.

CASTILHOS, R.; ROSSI, C.A. Subindo o morro: consumo, posição social e distinção entre famílias de classes populares. In: ROCHA, A.; SILVA, J. (Org.) Consumo na base da pirâmide: estudos brasileiros. Rio de Janeiro: Mauad X, 2009.

CHAUVEL, M.A. Consumidores insatisfeitos: uma oportunidade para as empresas. Rio de Janeiro: Mauad, 2000.

CHAUVEL, M.A.; MATTOS, M. Consumidores de baixa renda: uma revisão dos achados de estudos feitos no Brasil. Cadernos Ebape, v.6, n.2, p.1-17, 2008.

CHAUVEL, M.A.; SUAREZ, M. Consumidores pobres e insatisfação pós-compra: "eles não têm respeito pela gente". In ROCHA, A.; SILVA, J. Consumo na base da pirâmide: estudos brasileiros, Rio de Janeiro: Mauad, 2009.

CHEBAT, J-C; DAVIDOW, M.; CODJOVI, I. Silent voices: why some dissatisfied consumers fail to complain. Journal of Service Research, v. 7, n. 4, p. 328-342, 2005.

CRIÉ, D. Consumers' complaint behaviour. Taxonomy, typology and determinants: towards a unified ontology. Journal of Database Marketing \& Consumer Strategy Management, v. 11, n. 1, p.60-79, 2003.

CRUZ, M. Segmento de baixa renda: definições estratégias com a utilização de Clusters. Revista Eletrônica Gestão e Serviços, v.1, n.2, p.147-161, 2010.

DA MATTA, R. Brasil: uma nação em mudança e uma sociedade imutável? Considerações sobre a natureza do dilema brasileiro. Revista Estudos Históricos, v. 2, n. 2, p. 204-219, 1988. 
FERNANDES, D.; SANTOS, C. Consumer complaining behavior in developing countries: the case of Brazil. Journal of Consumer Satisfaction, Dissatisfaction and Complaining Behavior, v. 20, p. 86-109, 2007.

FITZPATRICK, M.; FRIEND, L.; COSTLEY, C. Dissatisfaction and distrust. Journal of Consumer Satisfaction, Dissatisfaction and Complaining Behavior, v. 17, p. 117-129, 2004.

FORBES, S. The effect of service quality and expectations on customer complaints. The Journal of Industrial Economics, v. 52, n. 1, p. 190-213, 2008.

FOX, G. Getting good complaining without bad complaining. Journal of Consumer Satisfaction, Dissatisfaction and Complaining Behavior, v. 21, p. 23-40, 2008.

FUNCHES, V. Consumer anger: causes and consequences. In: SOCIETY FOR CONSUMER PSYCHOLOGY, 2008, New Orleans. Proccedings... New Orleans, 2008.

GILL, R. Análise do discurso. In: BAUER, M; GASKELL, G. Pesquisa qualitativa com texto, imagem e som: um manual prático. 3.ed., Petrópolis, RJ: Vozes, 2009.

GINI, A. Work, identity and self: how we are formed by the work we do. Journal of Business Ethics, v. 17, n. 7, p. 707-714, 1998.

GUESALAGA, R., MARSHALL, P. Purchasing power at the bottom of the pyramid: differences across geographic regions and income tiers. Journal of Consumer Marketing, v.25, n.7, p.413418, 2008.

GUEST, G.; BUNCE, A.; JOHNSON, L. How many interviews are enough?: An experiment with data saturation and variability. Field Methods, v.18, n.1, p.59-82, 2006.

HALSTEAD, D.; DRÖGE, C.; COOPER, M.B. Product warranties and post-purchase service: a model of consumer satisfaction with complaint resolution. The Journal of Services Marketing, v. 7, n. 1, p. 33-40, 1993.

HALSTEAD, D.; JONES, M.; COX, A. Satisfaction theory and the disadvantaged consumer. Journal of Consumer Satisfaction, Dissatisfaction and Complaining Behavior, v. 20, p. 15-35, 2007.

HEUNG, V.; LAM, T. Customer complaint behaviour towards hotel restaurant services. International Journal of Contemporary Hospitality Management, v. 15, n. 5, p. 283-289, 2003.

HOFSTEDE, A. et al. Projective techniques for brand image research: two personification-based methods explored. Qualitative Market Research: an International Journal, v. 10, n. 3, p. 300309, 2007.

INSTITUTO DE DEFESA DO CONSUMIDOR. Setor financeiro e planos de saúde lideram ranking de atendimentos do Idec em 2011. 1 março de 2012. Disponível em: < http://www.idec.org.br/em-acao/em-foco/setor-financeiro-e-planos-de-saude-lideramranking-de-atendimentos-do-idec-em-2011>. Acesso em: 13 set. 2012.

KNIGHTS, D.; STURDY, A.; MORGAN, G. The consumer rules? An examination of the rhetoric and "reality" of marketing in financial services. European Journal of Marketing, v. 28, n. 3, p. 42-54, 1994.

LAPRÉ, M.; TSIKRIKTSIS, N. Organizational learning curves for customer dissatisfaction: heterogeneity across airlines. Management Science, v. 52, n. 3, p. 352-366, 2006.

LEVY, S. Interpreting consumer mythology: structural approach to consumer behavior focuses on story telling. Marketing Management, v. 2, n. 4, p. 4-9, 1994.

LIMEIRA, T. O potencial do mercado de baixa renda. In: PARENTE, J.; LIMEIRA, T.; BARKI, E. 
Varejo para a baixa renda, Porto Alegre: Bookman, 2008.

MATTOSO, C.; ROCHA, A. Building, losing and reconstructing social identities: an investigation into the symbolic use of credit by poor consumers in Brazil. Latin American Business Review, v. 9, n. 3/4, p. 227-255, 2008.

MILLER, D. Teoria das compras: o que orienta as escolhas dos consumidores. São Paulo: Nobel, 2002.

MOTTA, F.P.; ALCADIPANI, R. Jeitinho brasileiro, controle social e competição. RAE: Revista de Administração de Empresas, v. 39, n. 1, p. 6-12, 1999.

MOUTINHO, L.; DIONÍSIO, P.; LEAL, C. Surf tribal behaviour: a sports marketing application. Marketing Intelligence \& Planning, v. 25, n. 7, p. 668-690, 2007.

NASCIMENTO, P.; YU, A.; SOBRAL, M.C. As orientações estratégicas da inovação em produtos populares. Revista de Administração Contemporânea, v.12, n.4, p.907-930, 2008.

NASIR, V. E-consumers complaints about on-line stores. Journal of Consumer Satisfaction, Dissatisfaction and Complaining Behavior, v. 17, p. 68-87, 2004.

NERI, M. (Coord.) A nova classe média: o lado brilhante dos pobres. Rio de Janeiro: FGV/IBRE, CPS, 2008. Disponível em: <http://www.cps.fgv.br/cps/ncm/>. Acesso em: 7 nov. 2009.

OLIVER, R. Satisfaction: a behavioral perspective on the consumer. 2.ed. New York: M. E. Sharpe, 2010.

ONYEASO, G. Are customers' dissatisfaction and complaint behaviors positively related? empirical tests. Journal of American Academy of Business, v. 11, n. 1, p. 18-24, 2007.

PARENTE, J.; BARKI, E. Valor no varejo direcionado ao segmento de baixa renda. In: PARENTE, J.; LIMEIRA, T.; BARKI, E. Varejo para a baixa renda. Porto Alegre: Bookman, 2008.

PARSONS, A. Non-functional motives for online shoppers: why we click. The Journal of Consumer Marketing, v. 19, n. 5, p. 380-392, 2002.

PATWARDHAN, A.; NOBLE, S.; NISHIHARA, C. The use of strategic deception in relationships. Journal of Services Marketing, v. 23, n. 5, p. 318-325, 2009.

PETRESCU, M.; BHATLI, D. Consumer behavior in flea markets and marketing to the bottom of the pyramid. Journal of Management Research, v.13, n.1, p.55-63, 2013.

PETTIGREW, S.; CHARTERS, S. Tasting as projective technique. Qualitative Market Research: an International Journal, v.1 1, n. 3, p. 331-343, 2008.

PHAU, I.; BAIRD, M. Complainers versus non-complainers retaliatory responses towards service dissatisfaction. Marketing Intelligence \& Planning, v. 26, n. 6, p. 587-604, 2008.

PINTO, M. O consumo de eletroeletrônicos em um grupo de baixa renda: relatos de uma etnografia. Revista de Administração da Universidade Federal de Santa Maria, v.6, n.3, p.527-545, 2013.

PONCHIO, M.; ARANHA, F. Necessidades, vontades e desejos: a influência do materialismo sobre a dívida de consumo dos paulistanos de baixa renda. In: ENCONTRO DA ANPAD, 31., 2007, Rio de Janeiro. Anais... Rio de Janeiro: ANPAD, 2007.

PRADO, K.; BRITO, E.; SERRALVO, F.; TOLEDO, G. A preferência pela marca no processo de decisão de compra: um estudo exploratório no segmento de baixa renda. Organizações em Contexto, v.10, n.19, 357-382, 2014. 
PRAHALAD, C.K. The fortune at the bottom of the pyramid: eradicating poverty through profits. New Jersey: Pearson Education, 2006.

PRAHALAD, C.K.; HAMMOND, A. Serving the world's poor profitably. Harvard Business Review, v. 80, n. 9, p. 48-57, 2002.

PRAHALAD, C.K.; HART, S. The fortune at the bottom of the pyramid. Strategy $\&$ Business, v. 26, p. 1-14, 2002.

PROJETO INDICADORES PÚBLICOS DE DEFESA DO CONSUMIDOR. 2.ed. 2011. Disponível em: http://portal.mj.gov.br/main.asp?ViewID=\{5E563276-03A5-4ED9-9750-

F3BB71A31277 $\}$ \&params $=$ itemID $=\{C C 2 C 797 F-7 E B E-43 F A-B 363-$

A8A5261523EA $\} ; \& U I P a r t U I D=\{2218 F A F 9-5230-431 C-A 9 E 3-E 780 D 3 E 67 D F E\}$. Acesso em 13 set. 2012.

RATNER, C. Educating the low-income consumer: some viewpoints from an action program. Journal of Consumer Affairs, v.2, n.1, p.107-114, 1968.

RICHINS, M. Negative word of mouth by dissatisfied consumers: a pilot study. Journal of Marketing, v. 47, n. 1, p. 68-78, 1983.

ROCHA, A.; ARAUJO, F.; MOTTA, P.C. Atitudes de consumidores de baixa renda em relação às restrições ao lazer. Revista Pensamento Contemporâneo em Administração, v.8, n.1, p.142163, 2014.

ROCHA, A.; SILVA, J. Consumo na base da pirâmide: um desafio para a pesquisa. In: ROCHA, A.; SILVA, J. (Org.) Consumo na base da pirâmide: estudos brasileiros. Rio de Janeiro: Mauad X, 2009. 255p.

ROCHA, E. Culpa e prazer: imagens do consumo na cultura de massa. Comunicação, Mídia e Consumo, v. 2, n. 3, p. 123-138, 2005.

ROOK, D. Let's pretend: projective methods reconsidered. In: BELK, R. (ed.) Handbook of qualitative research methods in marketing, Northampton: Edward Elgar, 2006.

ROSE, R.; NEIDERMEYER, M. From rudeness to road rage: the antecedents and consequences of consumer aggression. Advances in Consumer Research, v. 26, n. 1, p. 12-17, 1999.

RUBIN, H.; RUBIN, I. Qualitative interviewing: the art of hearing data. 2.ed., Thousand Oaks: Sage, 2005.

SANTOS, C.; FERNANDES, D. A construção de uma tipologia dos consumidores para resposta à insatisfação. BASE - Revista de Administração e Contabilidade da UNISINOS, v.7, n.1, p.2541, 2010.

SECRETARIA DE ASSUNTOS ESTRATÉGICOS. Vozes da Classe Média - É ouvindo a população que se constroem políticas públicas adequadas. Brasília: Marco Zero, 2012.

SILVA, H.; PARENTE, J. O mercado de baixa renda em São Paulo: um estudo de segmentação baseado no orçamento familiar. In: ENCONTRO DA ANPAD, 31., 2007, Rio de Janeiro. Anais... Rio de Janeiro: ANPAD, 2007.

SINGH, J. A typology of consumer dissatisfaction response styles. Journal of Retailing, v. 66, n. 1, p. 57-99, 1990.

SISTEMA NACIONAL DO CONSUMIDOR. Boletim Sindec 2012. Disponível em: <http://portal.mj.gov.br/main.asp?View=\{5E563276-03A5-4ED9-9750-

F3BB71A31277 $\} \&$ BrowserType $=$ NN\&LangID=pt-br\&params=itemID\%3D $\{$ C5D2F7FC-1D58- 
4C86-B3AD-9F321CABCC3B $\} \% 3 B \& U I P a r t U I D=\{2218 F A F 9-5230-431 C-A 9 E 3-$

E780D3E67DFE\}>. Acesso em: 10 fev., 2014.

SPIGGLE, S. Analysis and interpretation of qualitative data in consumer research. Journal of Consumer Research, v. 21, n .3, p. 491-503, 1994.

STURDIVANT, F.; WILHELM, W. Poverty, minorities, and consumer exploitation. In: STURDIVANT, F. (ed.). The ghetto marketplace. New York: Free Press, 1969.

TOYER, A. Consumer education and low-income families. Journal of Consumer Affairs, v.2, n.1, p.114-120, 1968.

WATARAI, F.; ROMANELLI, G. Trabalho e identidade de adolescentes do sexo masculino de camadas populares. In: SIMPÓSIO INTERNACIONAL DO ADOLESCENTE, 1., São Paulo, 2005. Disponível em: <http://www.proceedings.scielo.br/scielo.php?script=sci_arttext\&pid=MSC000000008200500 0200089\&lng=en\&nrm=abn>. Acesso em: 21 fev. 2010.

WILL, V.; EADIE, D.; MacASKILL, S. Projective and enabling techniques explored. Marketing Intelligence \& Planning, v. 14, n. 6, p. 38-43, 1996.

WOOD, V.; PITTA, D.; FRANZAK, F. Successful marketing by multinational firms to the bottom of the pyramid: connecting share of heart, global "umbrella brands", and responsible marketing. Journal of Consumer Marketing, v. 25, n. 7, p. 419-429, 2008.

ZILBER, S.; SILVA, F. Investigação sobre a existência de inovações disruptivas das grandes empresas multinacionais para o mercado brasileiro de baixa renda. Produção, v.23, n.2, p.283296, 2013. 